\section{TECHNICAL ASSESSMENT OF AN OIL-FIRED RESIDENTIAL COGENERATION SYSTEM \\ PROJECT REPORT}

Roger J. McDonald

January 1993
Prepared for:

Building Equipment Division

office of Building Technologies

U.S. Department of Energy

Washington, D.C. 20585

\section{RECEIVED JUN 10 PSS OSTI}

Energy Efficiency and Conservation Division DEPARTMENT OF APPLIED SCIENCE

BROOKHAVEN NATIONAL LABORATORY UPTON, LONG ISLAND, NEW YORK 11973 1 


\section{TECHNICAL ASSESSMENT OF AN OIL-FIRED \\ RESIDENTIAL COGENERATION SYSTEM}

Project Report

Roger J. McDonald

January 1993

Energy Efficiency \& Conservation Division

Department of Applied Science

Brookhaven National Laboratory

Upton, New York 11973

This work was performed under the auspices of the U.S. Department of Energy Washington, D.C. Under Contract No. DE-AC02-76CH00016 


\section{DISCLAIMER}

This report was prepared as an account of work sponsored by an agency of the United States Government. Neither the United States Government nor any agency thereof, nor any of their employees, nor any of their contractors, subcontractors, or their employees makes any warranty, express or implied, or assumes any legal liability or responsibility for the accuracy, completeness, or usefulness of any information, apparatus, product or process disclosed, or represents that its use would not infringe privately owned rights. Reference herein to any specific commercial product, process, or service by trade name, trademark, manufacturer, or otherwise, does not necessarily constitute or imply its endorsement, recommendation, or favoring by the United states Government or any agency thereof. The views and opinions of authors expressed herein do not necessarily state or reflect those of the United States Government or any agency, contractor, or subcontractor thereof. 
The definition of cogeneration, within the context of this project, is the simultaneous production of electricity and heat energy from a single machine. This report will present the results of an engineering analysis of the efficiency and energy-conservation potential associated with a unique residential oil-fired cogeneration system that provides both heat and electric power. The system operates whenever a thermostat signals a call for heat in the home, just as a conventional heating system. However, this system has the added benefit of cogenerating electricity whenever it is running to provide space heating comfort. The system is designed to burn No. 2 heating oil, which is consumed in an 11-horsepower, two cylinder, 56.75-cubic-inch, 1850-RPM diesel engine. This unit is the only pre-production prototype residential No. 2 oil-fired cogeneration system known to exist in the world. As such, it is considered a landmark development in the field of oil-heat technology.

The study used a direct thermal efficiency measurement technique developed by Brookhaven National Laboratory to precisely determine the efficiency of the heating system based on enthalpy (heat) flow measurements into and out of the cogeneration unit. Electrical power output was measured concurrently. Stack (exhaust) emissions were also characterized and measured. Comparative noise level measurements were also obtained during the evaluation.

General information on the background of the Brookhaven National Laboratory - Combustion Equipment Technology Program (Oi1-Heat R\&D), the oil heat industry, the oil-heat market, residential cogeneration concepts, and the Model Alpha-550 prototype cogenerator manufactured by Intelligen Energy Systems, Inc. is presented in section 1.0 and section 2.0 of this report. Section 3.0 presents the various measurement techniques and procedures. Test data are given in section 4.0. Conclusions and Recommendations are included in Sections 5.0 and 6.0 , respectively.

The cogenerator produced $4.8 \mathrm{kw}$ of electric power under steady operating conditions. Its output is nominally $5 \mathrm{kw}$ on a cold start, dropping somewhat over time as the generator unit comes up to constant operating conditions and temperatures. The cogenerator has a combined system efficiency of $92.8 \pm 4.4 \%$ includiry its electrical output, hydronic (hot water output), and warm-air output. This represents a new high-end reference mark for the efficiency range of oil-fired residential heating equipment. If the warm-air component is not used at all, the combined efficiency drops to 71.5 $\pm 1.2 \%$. The measured emissions are representative of those expected for a diesel engine of this size and type. The noise level was within the measurement error of noise levels obtained at BNL during the operation of both an oil-fired furnace and boiler. 


\section{ACKNOWLEDGMENTS}

The author is pleased to acknowledge the outstanding contributions made by the staff of the BNL Combustion Equipment Technology Laboratcry (CETL) in support of this study. Special note is made of the work of Mr. Yusuf Celebi who manages the CETL on a day to day basis and was responsible for the supervision of the work described in testing the cogenerator as well as preliminary data reduction. 
Executive Summary . . . . . . . . . . . . . . . .

Acknowledgments . . . . . . . . . . . . . . . . . iv

1. Introduction . . . . . . . . . . . . . . . 1

2. Background . . . . . . . . . . . . . . . 3

2.1 BNL Combustion Equipment Technology Laboratory . 13

2.2 Oil-Fired Cogeneration System -
Intelligen Model Alpha-550. . . . . . . . . 4

3. Test Methodology . . . . . . . . . . . . . 8

3.1 Measurement Technique . . . . . . . . . . . 8

3.1.1 Thermal Efficiency Measurement Technique Hydronic Boilers .. . . . . . . 8

3.1.2 Thermal Efficiency Measurement Technique Warm Air Systems . . . . . . . . 10

3.1.3 Emissions Measurements . . . . . . 10

3.1.4 Electrical Power Output . . . . . . . 13

3.1 .5 Noise Levels . . . . . . . . . . 13

3.2 Combustion Laboratory Facilities . . . . . . . 13

3.2 .1 Description of Hydronic Boiler Test
Stand \& Instrumentation . . . . . . 13

3.2 .2 Calibration . . . . . . . . . . . 14

4. Test Results . . . . . . . . . . . . . . 16

5. Conclusions . . . . . . . . . . . . . . . . 22

6. Recommendations . . . . . . . . . . . . . . 25 


\section{LIST OF FIGURES}

Page

Figure 1: Alpha-550 Cogenerator - Intelligen

Energy Systems, Inc. • . . . . . . . . . . . 2

Figure 2: Schematic of the Cogenerator system showing

Energy Flows... . . . . . . . . . . 6

Figure 3: Internal Components of the Intelligen

Alpha-550 . . . . . . . . . . . . . . . . . . 7

Figure 4: Dilution Tunnel and Filter Trap

Sampling System . . . . . . . . . . . .

Figure 5: Test Results of overall Efficiency Versus Load

for the Intelligen Alpha-550 Cogenerator. .

Figure 6: Results of Emission Measurements, $\mathrm{NO}_{x} / \mathrm{CO} /$ Hydrocarbons, Made During Steady-state operation for the Intelligen Alpha-550 Cogenerator. .

Figure 7: Results of the Emission Measurements, Particulates, Made During steady-state and Cyclic operation for the Intelligen Alpha-550 cogenerator . . . . . . . . .

Figure 8: Results of the Noise Level Measurements, Made During steady-State operation of the Intelligen Alpha-550 . . . . . . . . . . . . . 


\section{LIST OF TABLES}

\section{Page}

Table 1: Emission Rates - Lbs Per Million Btu steady-State operation................ . . 20 


\subsection{INTRODUCTION}

This report presents the results of an engineering analysis of the energy conservation potential associated with a residential oilfired cogeneration system that provides both heat and electric power. The system operates whenever a thermostat signals a call for heat in the home, just as with a conventional system. However, this system has the added benefit of cogenerating electricity whenever it is running to provide space heating comfort. A laboratory study was conducted to measure the efficiency performance, operating characteristics, emissions, and noise levels of the only preproduction prototype residential oil-fired cogeneration system known to exist in the world. As such it is considered a landmark development in the field of oil-heat technology. Ten of these systems are currently installed at various sites in New England as part of a test marketing and field evaluation effort being conducted by the manufacturer.

The goal of this project was to define the potential energy conservation benefits of using the concept as a replacement for existing heating systems and also for the construction of new housing. In this regard, the study used a direct thermal efficiency measurement technique developed by Brookhaven National Laboratory (BNL) to precisely determine of the efficiency of the heating system based on enthalpy (heat) flow measurements into and out of the cogeneration unit. Stack (exhaust) emissions were characterized and measured. Emission measurements included particulates, carbon monoxide, carbon dioxide, nitrous oxides, and hydrocarbons. Electrical power output was measured. Comparative noise measurements were made given the limitations of the combustion Equipment Technology Laboratory (CETL) at BNL, which was not designed with this purpose in mind.

The Model: Alpha-550 (Figure 1), a pre-production prototype, 5kilowatt, residential cogeneration system was loaned to BNL for evaluation and testing by the manufacturer, Intelligen Energy systems Inc. (Intelligen). The system is designed to supply: hot water for hydronic baseboard heating systems, 5 kilowatts of electricity during operation, and in addition, a significant amount of warm air which is used to heat the space where the unit is installed or which can be ducted to other parts of the living space, if the unit is located in an unheated area in the house.

The system is designed to burn No. 2 heating oil, which is consumed in an 11-horsepower, two-cylinder, 56.75-cubic- inch, 1850RPM diesel engine manufactured by Lister-Petter, Inc., custom configured for Intelligen. The engine powers a single-phase induction generator, which is also custom configured for Intelligen. The heat from the water-cooled engine is combined with the heat recovered from a tube-in-shell exhaust heat exchanger and is circulated to the hydronic baseboard zories located throughout the house, exactly as in a conventional hydronic boiler system. 
The unit is controlled by a proprietary system designed by Intelligen, based on a Motorola MC68HC705B5 microprocessor chip with input from standard heating-system controls. The control system has an input/output port for connecting a service terminal for diagnostic checks.

The Intelligen unit is specifically designed as a cogenerator, not an emergency generator. If the local utility power grid, which normally provides electricity to the house, is down, for reasons such as downed power lines, the Intelligen Alpha-550 will not operate. This situation is exactly the same as when the power is off in a home equipped with a normal heating system. A conventional boiler or furnace will not provide heat, because it needs electricity to power the electrical components.

The Intelligen unit is designed to take advantage of the efficiencies and economics of cogeneration, which is defined here as the simultaneous generation of electricity and useful heat energy. The major advantage is that the efficiency of the overally system can be much higher than the typical 33\% obtained with a fossil-fueled electric utility power plant (including transmission line losses). The residential cogeneration system has the potential for $90 \%$ efficiency or better.

The efficient use of primary energy sources including fossil fuels (oil, gas, and coal), is one of the important goals of the United States and a mission objective of the U.S. Department of Energy (DOE) as described in the National Energy strategy (First Edition 1991/92). The technical assessment of this cogenerator was conducted for the DOE in response to technical inquiries and interests of the U.S. oil-heat industry and the energy conservation community at large.

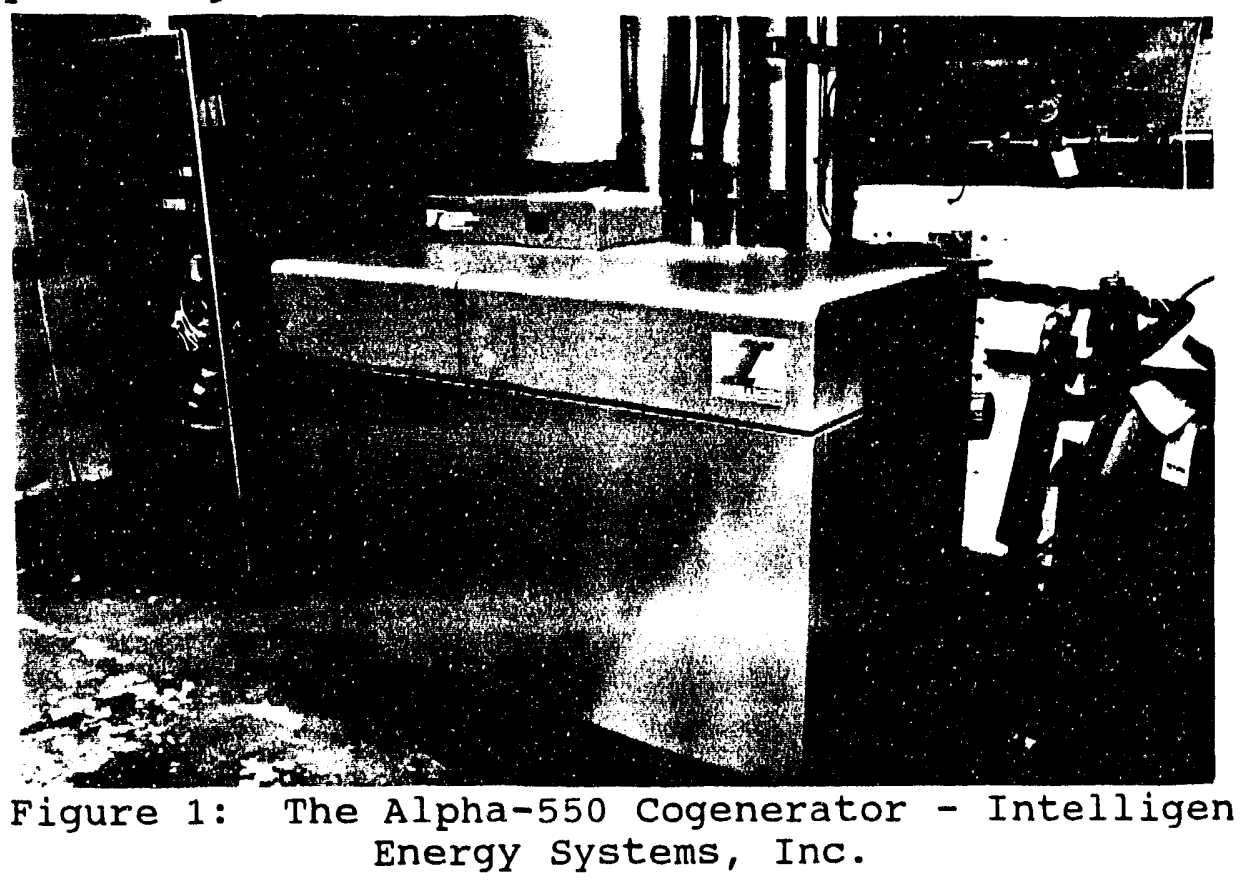




\subsection{BACKGROUND}

\subsection{BNL - Combustion Equipment Technology Laboratory}

oil is used to heat more than 12 million homes in the United states. Over $80 \%$ of these homes are located in the New England, Mid-Atlantic, and North Central states where colder climates and higher electricity prices prevail. Most of these are in suburban areas where access to natural gas lines is limited. These residences consume approximately two quads of oil per year, more than $\$ 10$ billion. The vulnerability of the oil-heat consumer to fluctuations in oil prices and availability of oil, the lack of alternative energy sources, the concern about acid rain in these areas, and the fragmented nature of the oil-heat industry's R\&D efforts has prompted the DOE to assist the private sector in developing a technology base from which advanced energy-efficient oil combustion systems can evolve.

Since 1976, DOE's office of Building Technologies (OBT), working through the BNL, has concentrated their efforts on upgrading the technology applied to residential and light commercial space-heating systems. Researchers at BNL's Combustion Equipment Technology Laboratory (CETL), in cooperation with academic and private sector organizations, are developing and evaluating innovative systems and components. These efforts assist in the effective transfer of the technology into the marketplace.

The accomplishments of the OBT/BNL program in combustion equipment technology are numerous. Their identification, characterization, and transfer of modern flame retention head burner technology is credited with projected savings of 1.7 quads of oil by the year 2000. Over the past decade, researchers at BNL have identified many energy saving space-heating retrofit options and evaluated potential benefits or deficiencies in the advanced technologies that are introduced into the marketplace. This technology base provides a solid foundation for advancing the stateof-the-art in residential oil heating and recognizes the importance of economic factors and consumer preferences.

\section{Research Focus}

The goal of the OBT's research in combustion equipment technology is to develop generic technical information and base technologies that will assist the oil-heat industry in producing and marketing the most efficient products possible. It seeks to achieve this goal by pursuing a fourfold set of objectives. First, scientists and engineers in the program are working to improve the steady-state performance and seasonal efficiency of conventional oil-fired space heating systems. Emphasis is placed on developing a base technology for low-firing-rate systems interfaced with efficient heat exchangers. Second, efforts are being directed at eliminating or minimizing performance degradation over time, mainly 
by correlating exhaust-gas and particulate emissions with performance and by introducing innovative control mechanisms. Third, the improvements from both of these efforts are being incorporated with the use of direct-venting subsystems for maximum efficiency. Finally, BNL/CETL is an independent and impartial third-party efficiency testing laboratory for evaluating new and unique combustion equipment concepts and designs intended to increase efficiency and save energy. The current assessment of an oil-fired cogeneration system, the first of its kind, is an example of this type of effort.

\section{Combustion Equipment Technology Laboratory}

The CETL at BNL is a unique facility equipped with four test stations, three for hydronic boiler (hot water) testing and one for warm-air furnace evaluations. A desk-top microcomputer system provides automated process control and gathers data for further analysis. The facility is also equipped with software to operate the equipment in both steady-state and cyclic modes.

The CETL is a DOE-designated "user facility" and offers many research opportunities to the private sector as well as to government laboratories. Typical activities, consistent with the energy conservation goals of DOE/OBT, include: performance analysis and characterization of advanced heating equipment designs (as is the case with the evaluation of a unique oil-fired cogeneration system); fuel atomization characterization for improved burner performance; stack-gas emissions analysis; fuel quality assessment; reduction of soot and fouling due to particulate emissions; reliability and safety characterization; and development of service and advanced diagnostic techniques.

\subsection{Oil-Fired Cogeneration System - Intelligen Model Alpha-550}

Residential energy loads fall into one of two general categories: 1) space and water heating loads, and 2) electrical loads including lighting, appliances, cooling, and many other devices powered by electricity. Historically, heating was a significantly larger energy load than that represented by electrical appliances, but in many cases, this is no longer true. Energy conservation technology has come of age in the residential buildings area. The use of high-efficiency appliances, windows, doors, insulation systems, shower heads, and other energy conservation and weatherization techniques have been widely adopted into existing and new housing stocks. Many homes have dramatically smaller space and water heating requirements. Electrical consumption has either remained constant or increased as new types of electrical devices are brought into the residential environment. The result is that the ratio of electric to heat energy requirements has been brought closer into balance and has made cogeneration of electricity and heat a more viable option. 
The concept of cogeneration dates back to when Thomas A. Edison construsted the first power plants in the large eastern cities in the United States and sought ways to locally use the waste heat from the boilers (used to power the electric generators) so that it could be sold for additional profit. The definition of cogeneration in this case is the simultaneous production of electricity and heat energy from a single machine.

Until recent changes in certain state utility regulations and the Federal Government's Public Utility Regulatory Policy Act, (PURPA) it was not considered economically viable to market cogeneration systems on the smallest scale, residential systems sometimes called micro-cogenerators. Other factors that make microcogenerators viable today include the availability of reasonablypriced, high-reliability engines and low-cost, high power microcomputer chips. Even now it is a matter questioned by some "experts." However, Intelligen Energy Systems Inc., jelieves it is a viable option and has already designed an oil-fired residential cogenerator system for the residential market.

The cogenerator basically consists of an engine, a generator, a heat exchanger, and controls. Figure 2 is a schematic of the system with its major components and illustrates the various energy flows which occur during operation. Heat given off by the engine (both jacket and exhaust) is transferred to the hydronic distribution system, while heat from the generator is transferred to the warm-air stream. Figure 3 shows the internal components of the Intelligen Alpha-550. The engine is on the right, the generator is on the left, and the controls are located on top of the generator.

The Intelligen system was designed with certain factors in mind, including:

1) power output - 5 kilowatts;

2) Low maintenance requirements - able to run a full heating season without service;

3) quiet operation - as quiet as a conventional boiler;

4) durability - the diesel engine would be the best available with a proven long-term life expectancy;

5) electrical interconnect - equipment would not depend on expensive frequency and voltage conditioners; an induction generator would be used;

6) System control - control of the cogenerator would be based on a proprietary protocol using a programmable microprocessor, including service diagnostics and multiple levels of safety built in to protect the unit;

7) room temperature control - existing/standard wall thermostats would be used to control circulators;

8) combustion air - outside air would be used to eliminate energy losses from induced infiltration;

9) costs - had to meet criteria for affordability of both the initial capital investment and life-cycle costs; 
10) utility acceptance - the cogenerator had to fit the requirement of the PURPA regulations and satisfy requirements imposed by the utility regarding safety, voltage regulation, and frequency matching.

BNL's evaluation of the Intelligen Alpha-550 was limited to laboratory tests only, and only the technical evaluation of efficiency, emissions, power output, and noise. This study did not evaluate long-term durability, use under field conditions, maintenance requirements, code acceptance, and utility acceptance. These issues are evaluated by the manufacturer in its own field trials of the ten pre-production prototype units currently underway.

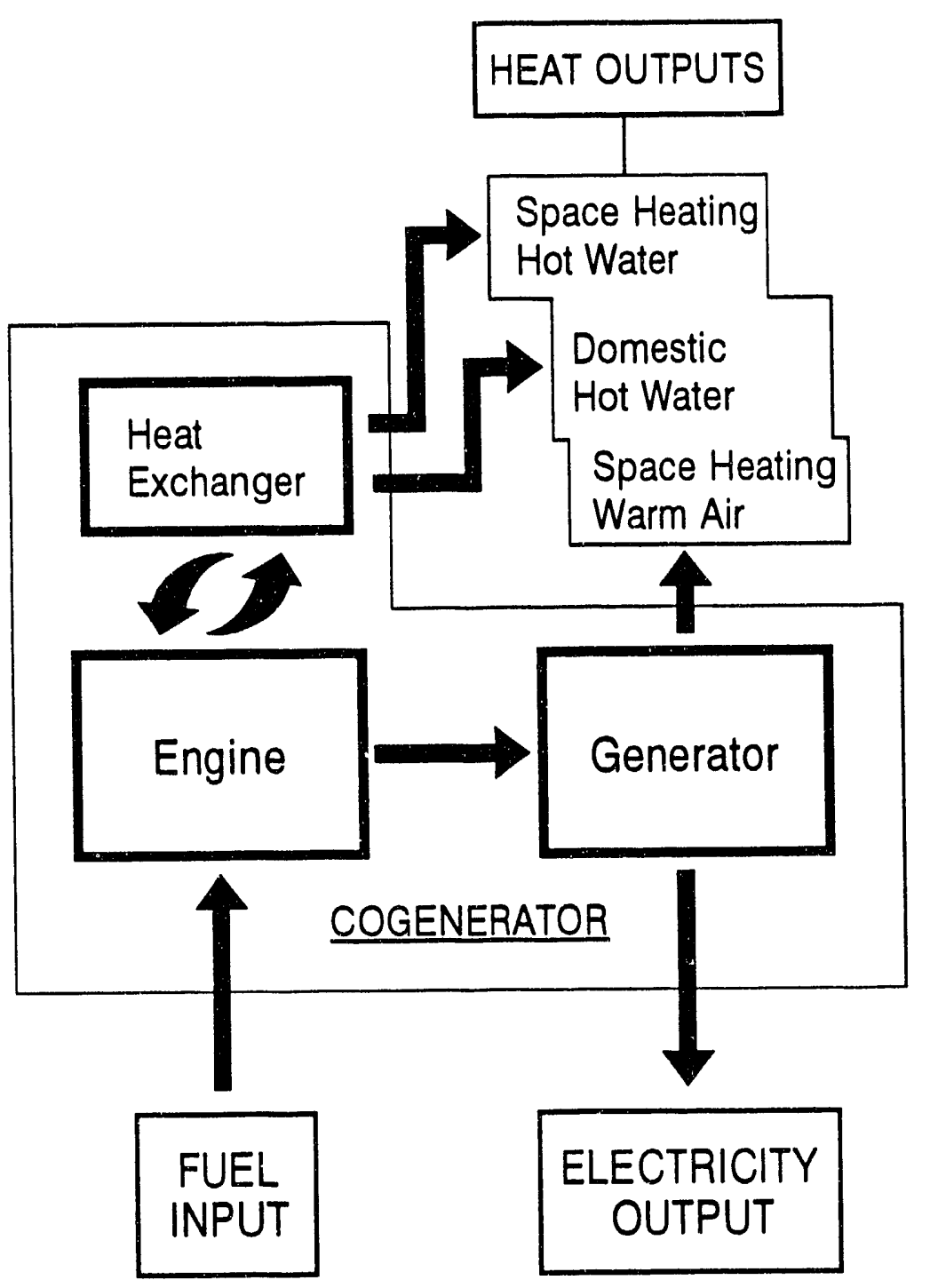

Figure 2: Schematic of the cogenerator system Showing Energy Flows. 


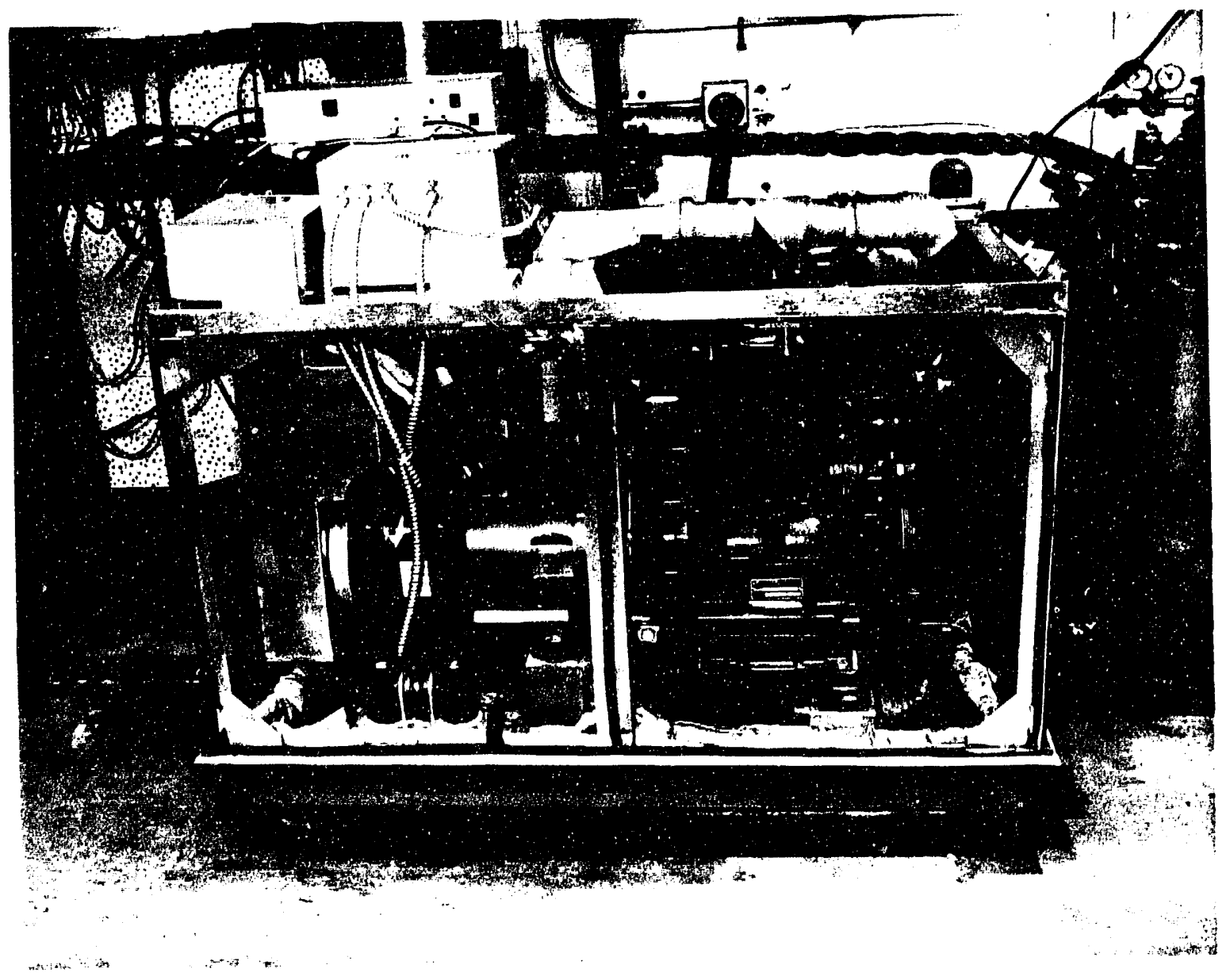

Figure 3: Internal Components of the Intelligen Alpha-550. 


\subsection{TEST METHODOLOGY}

\subsection{Measurement Technique}

In this evaluation of the oil-fired cogenerator, several
factors were considered which required different analysis techniques. First, the unit is controlied by a thermostat just like a hydronic (hot water) boiler. The method used to evaluate the hydronic heating efficiency component of its output is described in section 3.1.1. Second, the unit also has a warm-air output component which must be accounted for in determining the overall efficiency of the system. This warm-air measurement is discussed in section 3.1.2. Third, the electrical power produced by the unit had to be measured. Finally, techniques to measure exhaust emissions and noise were also applied.

\subsubsection{Thermal Efficiency Measurement Technique - Hydronic Boilers}

The enthalpy (heat) flow technique directly measures the efficiency of heating equipment efficiency during steady-state (continuous) and cyclic (intermittent) burner operation. The quantity of heat transferred to the boiler water (heat transfer medium) is measured and compared with the corresponding chemical heat energy content of the fuel (gas or oil), which is released during the combustion process. The efficiency of operation $\eta$ is defined to be the following ratio:

$$
\eta=\frac{\text { Heat transferred to boiler water }}{\text { Total heat available from combustion of fuel oil }}
$$

The enthalpy flow measurement technique does not depend on any simplifying assumptions (except that jacket loss is true loss), and results from basic first laws of energy conservation and physics. consequently, the accuracy of the test results is limited only by the accuracy of measurement of the physical quantities of interest (mass flow rates, temperatures, caloric (energy) content of the fuel, heat capacities, etc.).

The physical quantities that were measured include:

(a) $\dot{m}_{w}$ - Water flow rate through boiler (pounds per minute)

(b) $\Delta T$ - Temperature rise across the boilex

$\Delta T=T_{\text {outlet }}-T_{\text {inlet }}($ degrees $F)$ 
(c) $\dot{m}_{\text {oil }}$-Fuel flow rate to burner (pounds per minute)

(d) $h_{\text {oil }}$ - Higher heating value of fuel (Btu per pound)

The heat transfer rate to the water is simply the product of the water mass flow rate, $C_{p}$, heat capacity (which is 1.0 for water), and rise in temperature.

$$
\dot{H}=\dot{m}_{w} \times C_{p} \times \Delta T
$$

Similarly, the heat available from the combustion of fuel is the product of the fuel mass flow rate and the higher heating value of the fuel.

$$
\dot{H}_{\text {total }}=\dot{M}_{\text {oil }} \times h_{\text {oil }}
$$

The steady-state efficiency $\left(\eta_{s}\right)$ is the ratio of these two quantities when all parameters measured are constant and invariant.

$$
\eta_{s}=\frac{\dot{m}_{w} \times \Delta T \times C_{p}}{\dot{m}_{o i 1} \times h_{o i 1}}
$$

The cyclic (intermittent) burner operation, which is the normal mode of operation of a residential heating system, is calculated by integrating the measured quantities over time. The overall efficiency at cyclic conditions is defined as the ratio of the time integrals of the quantities that indicate total heat recovered and total heat available in the fuel consumed.

$$
\eta_{0}=\frac{\int\left(\dot{m}_{w} \times \Delta T\right) d t}{\int\left(\dot{m}_{o i 1} \times h_{o i 1}\right) d t}
$$

As noted above, the enthalpy flow technique is a fundamental method for directly determining the efficiency of heating equipment. It can be considered a "standard" method (traceable to basic laws) 
whose accuracy depends solely on the accurate measurement of the above mentioned quantities.

\subsubsection{Thermal Efficiency Measurement Technique - Warm-Air systems}

A similar method was applied to measure the thermal output of the cogenerator to the air stream. This measurement was made with much less accuracy due to the configuration of the warm-air venting from the enclosure housing of the cogenerator. A length of rectangular ducting was attached to the housing to allow acrosssectional hot-wire anemometer to be used to measure exit velocities, and temperatures also were logged. This manual technique is estimated to have an error of approximately $\pm 15 \%$ of the recorded thermal efficiency component representing the warm air supplied by the unit. This can be compared with the error in the hydronic component measurement, which is $\pm 2 \%$ of the efficiency measured.

\subsubsection{Emissions Measurements}

Exhaust emissions measurements were made during steady-state operation of the cogenerator system. These included hydrocarbons, carbon monoxide, oxygen (excess air), particulates, and $\mathrm{NO}_{x}$, all under the standard conditions, adjustments, and fuel/air ratio of the diesel engine as it was delivered to BNL.

\section{Particulates}

To quantitatively determine the mass emission rate of soot and non-gas-phase hydrocarbons, a filter-trap dilution tunnel technique was applied (Figure 4). A dilution tunnel was designed and fabricated. The combustion products from the cogenerator are mixed with ambient air in a ratio of 10 parts room air to one part exhaust and then sampled. The dilution tunnel was constructed to prevent exhaust-gas pulsations from affecting the measurement and also to allow the exhaust gases to reach actual environmental conditions so that the particulate emission levels from the unit could be accurately measured. This technique results in a measurement that can be compared with particulate emission rates reported for other types of heating systems in pounds per thousand gallons of fuel consumed.

\section{Hydrocarbons}

Gas-phase hydrocarbons were measured by pulling a gas sample directly from the first section of the exhaust system very close to the cogenerator. The gas-phase hydrocarbon levels were measured using a Model 400A Hydrocarbon Analyzer (Beckman Industrial Corp.), which uses a flame-ionization detection method. The sensor is a burner in which a regulated flow of sample gas passes through a flame sustained by regulated flows of air and a carbon-free fuel gas ( $40 \%$ hydrogen/60\% nitrogen). In the mixed flame the hydrocarbon components of the sample stream undergo a complex ionization that produces electrons and positive ions. Polarized electrodes collect 


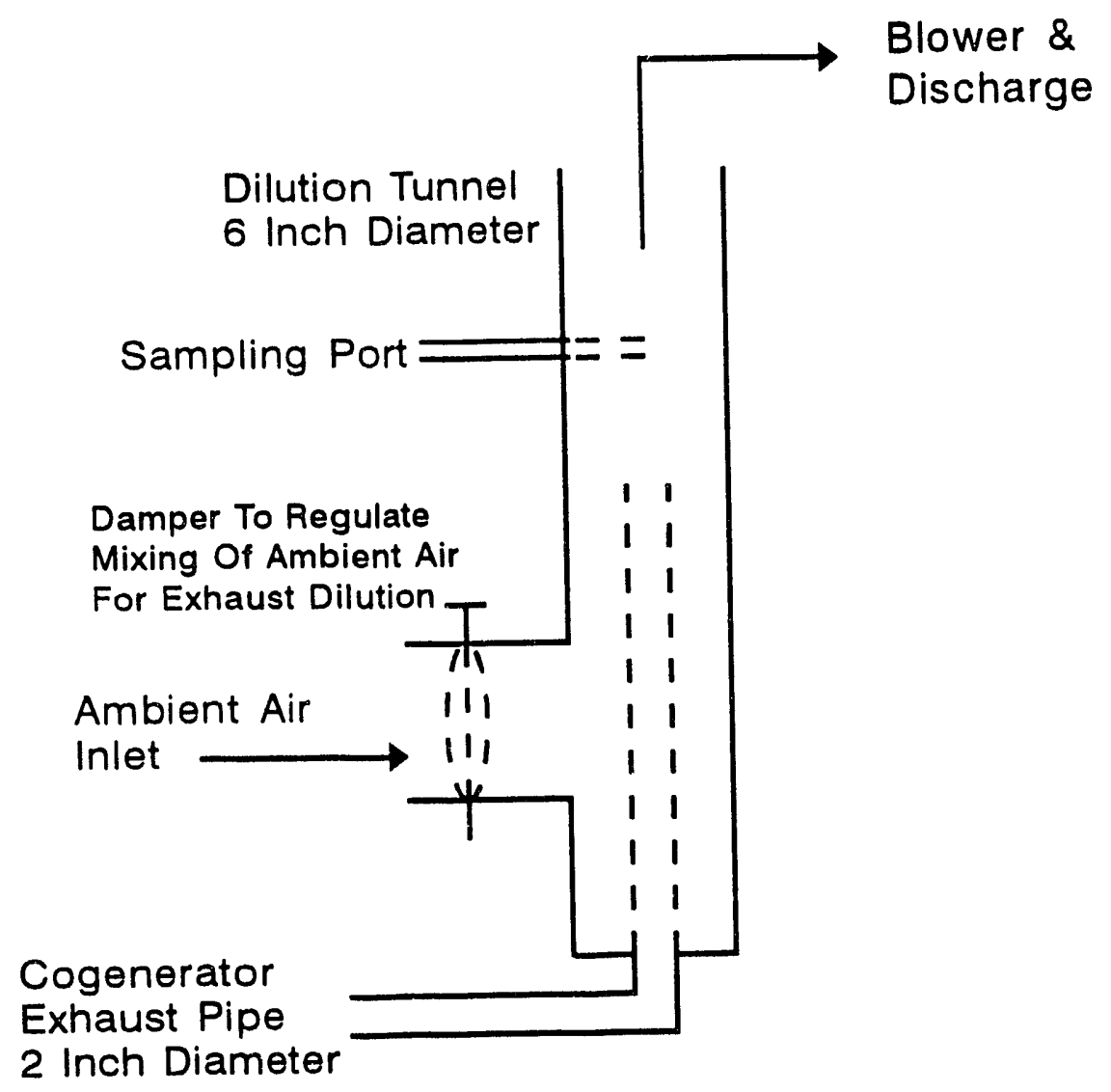

Dilution Tunnel

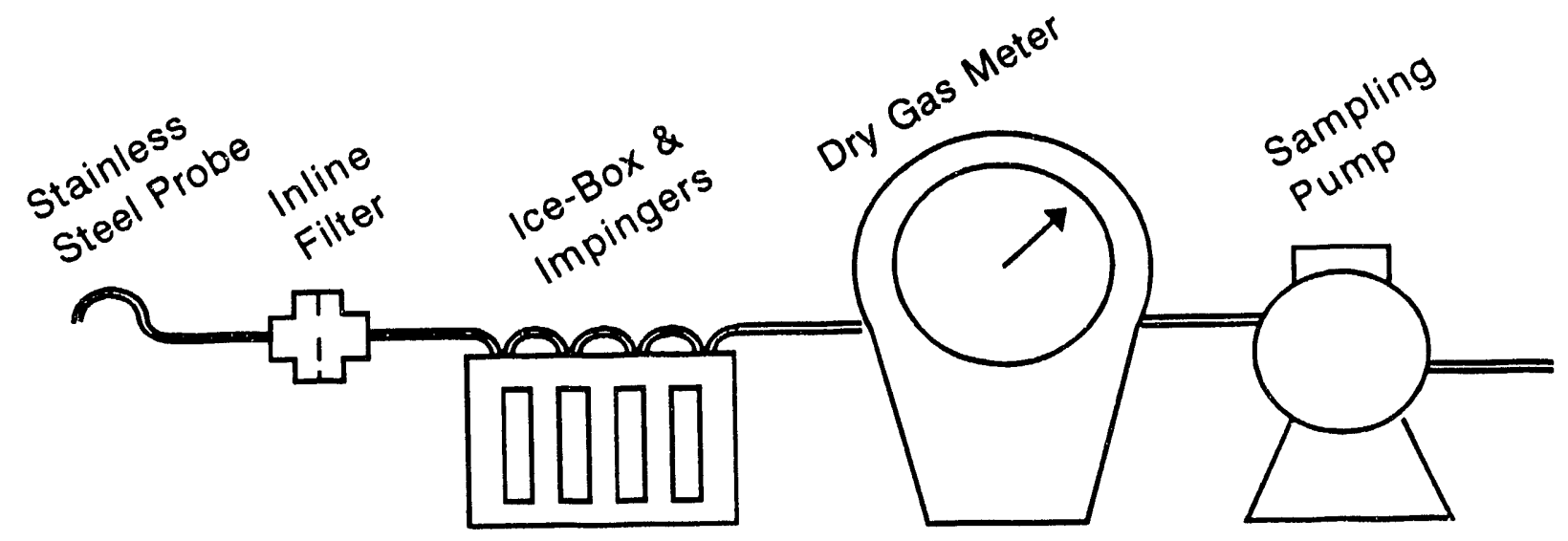

Filter \& Sampling System

Figure 4: Dilution Tunnel and Filter Trap Sampling system. 
these ions, causing current to flow through electronic measuring circuitry. Current flow is proportional to the rate at which carbon atoms enter the burner. Before starting a test run the system is allowed to reach operating temperature. The sampling probe is then installed and sampling is begun.

\section{Carbon Monoxide}

The instrument used was a Beckman Model 865 carbon monoxide analyzer. This analyzer produces infrared radiation from two identical sources. The two beams then pass through a chopper, which interrupts them at a frequency of $10 \mathrm{~Hz}$. The beams then pass through optical filters to reduce background interference from other infrared-absorbing components. The infrared beams then pass through two cells, one a reference cell containing a non-absorbing background gas, the other a sample cell containing a continuous flowing sample. During operation a portion of the infrared radiation is absorbed by carbon monoxide in the sample, with the percentage of infrared radiation absorbed being proportional to the concentration of carbon monoxide.

The detector is a "gas microphone" based on the Luft principle. It converts the difference in energy between the sample and reference cell to a capacitance change. This capacitance change, proportional to the concentration of carbon monoxide, is amplified and indicated on a meter.

\section{Nitrous oxide (NO) and Nitrogen Dioxide $\left(\mathrm{NO}_{2}\right)-\mathrm{NO}_{x}$}

The instrument used was a Beckman Model 955 NO/NO Chemiluminescence analyzer. The chemiluminescence detection technique is based on the principle that nitric oxide (NO) reacts with ozone $\left(\mathrm{O}_{3}\right)$ to produce nitrogen dioxide $\left(\mathrm{NO}_{2}\right), 10 \%$ electronically excited nitrogen dioxide $\left(\mathrm{NO}_{2}{ }^{\circ}\right)$ and oxygen. Following the $\mathrm{NO}-\mathrm{O}_{3}$ reaction, the $\mathrm{NO}_{2}{ }^{-}$molecules immediately revert to $\mathrm{NO}_{2}$. This process creates photons that produce a light emission directly proportional to the NO concentration in the sample. The intensity of the resulting light emission is then measured by a photomultiplier tube and associated electronics. $\mathrm{An} \mathrm{NO}_{2}$ to $\mathrm{NO}$ converter is used for $\mathrm{NO}_{x}$ $\left(\mathrm{NO}+\mathrm{NO}_{2}\right)$ analysis.

\section{Oxygen}

The content of flue-gas oxygen was measured with a Beckman Model 755 para-magnetic analyzer. Air/fuel ratios can be expressed in several ways, including excess air, percent $O_{2}$, and percent $\mathrm{CO}_{2}$. The last is most commonly used in the residential heating field, and all measured percent $\mathrm{O}_{2}$ readings were converted (based on the specific fuel composition) to percent $\mathrm{CO}_{2}$ and percent excess air. 


\subsubsection{Electrical Power output}

Electrical power output was measured using a microprocessorcontrolled electric power/demand measuring, indicating, and recording analyzer. Specifically a Model series 808 analyzer manufactured by Dranetz Technologies Inc. was equipped with Dranetz Model TR-2012 clamp-on current probes and the standard clip-on voltage input cable. The unit is designed to monitor true RMS voltage, RMS current (amps), and power. Measurements were made on the "house" side of a "BUCK-BOOST" Square-D Co. transformer used to convert the laboratory's 208-volt supply to the 240 volts that the cogenerator is designed to supply (which matches the standard residential voltage supplied in a private home).

\subsubsection{Noise Levels}

Noise levels were measured using a General Radio Precision Sound-Level Meter and Analyzer, Model No. 05129. Weighted levels $(A \& C)$ were recorded as well as specific $d B$ levels in ten frequency ranges. Measurements were made at a distance of 5 feet from the front and center of the cogenerator at a height of 60 inches from the floor (typical for human ear). Comparative measurements were obtained on the same day for a warm-air furnace and a boiler (both oil-fired), also at a distance of 5 feet from the front and center of the units and 60 inches above the floor. However, the BNL Combustion Equipment Technology Laboratory was not designed for accurate sound-level measurements; hence, the data are subject to the limitations of the laboratory's environment. The measurements are provided for general comparisons only and should not be used as a true indication of sound-level performance.

\subsection{Combustion Laboratory Facilities}

\subsubsection{Description of the Hydronic Boiler Test stand and Instrumentation}

The test facility was built to measure thermal efficiencies of various hydronic boilers under controlled conditions, and was provided with means to control water-flow rates and inlet water temperatures to accommodate boilers of different designs. The test facilities at BNL were designed and built to produce maximum measurement accuracy and reliability. The following is a brief description of the instrumentation and test stand:

(1) $\dot{m}_{\mathrm{w}}$ Turbine-type volumetric flow meters are used to
measure the water-flow rates through the boilers.
The temperature of the water is also measured with
a T-type thermocouple, which allows a computation
to be made resulting in the determination of the
mass-flow rate of water through the system. 
(2) $\Delta \mathrm{T}$ A thermopile is used to measure the rise in temperature across the boiler. This device consists of 20 thermocouples wired in an array in such a way as to provide a differential temperature reading between the water inlet and outlet of the boiler.

(3) $\dot{m}_{\text {fucl }} \quad$ Turbine-type flow meters are also used to measure the fuel volume-flow rate. A thermocouple is used to convert volume-flow rates to mass-flow rates for oil, knowing the fuel density and viscosity, which are measured separately.

(4) $h_{\text {fucl }}$ The fuel heating value is measured by an oxygen bomb calorimeter following the appropriate ASTM procedure for oil, and by sample constituent analysis (ASTM procedure) for gas.

(5) A desk-top computer coupled with a multichannel data acquisition and control system is used to log experimental data and provide test system control.

\subsubsection{Calibration}

To maintain a high degree of accuracy, calibration checks of all measured quantities are performed at least once daily (except as noted below). The techniques used for each quantity are explained below.

(1) $\dot{m}_{w}$ The water flow-rate measurement is calibrated gravimetrically using a platform balance and timer. Water is allowed to flow into a 55-galion drum mounted on the balance, which is freestanding. The rate at which the water mass increases in the drum is measured directly and then compared to the rate displayed on the data acquisition and control unit. The maximum uncertainty in the calibration procedure is $<0.1 \%$ while the uncertainty in $\dot{\mathrm{m}}_{\mathrm{w}}$ is $<0.5 \%$.

(2) $\Delta T$ The thermopile system is checked and verified daily against secondary standard platinum resistance thermometers (RTD-type) mounted in the water flows.

(3) $\dot{\mathfrak{m}}_{\text {oil }}$ The oil flow is calibrated gravimetrically using a balance and a timer. Oil is allowed to flow into a large flask atop a balance, and the rate at which the oil mass increases is measured. This rate is compared to the rate displayed on the data aciuisition and control unit. The maximum uncertainty in the calibration procedure is $<0.1 \%$, while the uncertainty in $\dot{\mathrm{m}}_{\mathrm{oil}}$ is $<0.5 \%$. 
(4) $h_{\text {oil }}$ A calibrated oxygen bomb calorimeter is used to measure the oil heating value. The manufacturer states uncertainty at $<0.1 \%$. 


\section{0 TEST RESULTS}

The electrical output of the Alpha-550 cogenerator unit was found to be $4.80 \pm 0.04 \mathrm{~kW}$ under steady operating conditions (one hour average, fully warmed-up). It produced a nominal $5.0 \mathrm{~kW}$ of electric power on a cold start, dropping slightly as the generator heated up to constant operating conditions. Consumption of fuel was measured and ranged from 0.54 to 0.57 gallons per hour (Btu/hr input range: 75,000 to 79,000$)$. The results of the thermodynamic efficiency test results for the unit are plotted in Figure 5, which indicates overall efficiency as a function of load, expressed in terms of the fraction of the time that the system was operating. The combined steady-state value is $92.8 \pm 4.4 \%$, including the electric output component $(21.3 \pm 0.2 \%)$, the hydronic output component $(50.2 \pm 1.0 \%)$, and the warm-air output component ( 21.3 $\pm 3.2 \%)$. If the warm-air component is not used, the combined efficiency could drop to $71.5 \pm 1.2 \%$. If the warm-air component is used, but not fully, such as heating a basement without proper insulation or heating controls, the efficiency may range anywhere from $71.5 \%$ to $92.8 \%$. The range will depend on the design of the basement (or any other uncontrolled space where the cogenerator might be installed) and the degree of communication (in terms of heating and ventilation) between the uncontrolled and controlled living spaces in the home. If a well-designed ducting system, properly sealed and insulated, is used, the efficiency will reflect the high end of the efficiency range, near $92.8 \%$. The error in the electric output component is very small $\pm 0.8 \%$ of the measurement, and the error in the hydronic output component is approximately \pm $2 \%$ of the measurement, the error in the warm air output component is much greater at $\pm 15 \%$ of the measurement. The degree of difficulty and the error and uncertainty in measuring the warm air thermal output precluded performing detailed cyclic tests of the system.

Figures 6,7 , and Table 1 show the results of the emission measurements. Figure 6 indicates the levels of nitrous oxides, carbon monoxide, and hydrocarbons (all in ppm) during steady state operation for two different fuels (standard No. 2 oil with a $0.25 \%$ sulfur content and No. 2 fuel with a low $0.05 \%$ sulfur content). Figure 7 indicates the emission rates of particulates (pounds of particulate per 1000 gallons of fuel) associated with the cogenerator during steady running conditions for the two fuel types mentioned above, and also the rate measured under cyclic conditions ( 5 minutes on, 15 minutes off) with the standard No. 2 fuel $(0.13 \%$ sulfur).

The results of the noise measurements are given in Figure 8 and indicate levels measured in ten frequency bands at a distance of 5 ft from the front of the unit being tested and at a level $5 \mathrm{ft}$ up from the floor, approximating the height of a human ear. Test data were recorded with the cogenerator operating by itself, and measurements were also recorded for a typical oil-fired, warm-air 
furnace and a typical oil-fired, cast-iron hydronic boiler. standard "A" weighted measurements of noise level performance are also shown in Figure 8. This "A" weighting is typical of the human perception of noise levels when all frequencies are heard in unison. All sound levels were measured on the same day within a one-hour period with a calibrated sound meter. Test conditions were made as equal as the laboratory environment would allow, although the BNL CETL facility was not designed as a sound testing laboratory. The results are included to give some general indication of the sound levels that would be expected when operating the cogenerator. This question has been a subject of interest voiced by many representatives of the oil-heat industry interested in this technology.

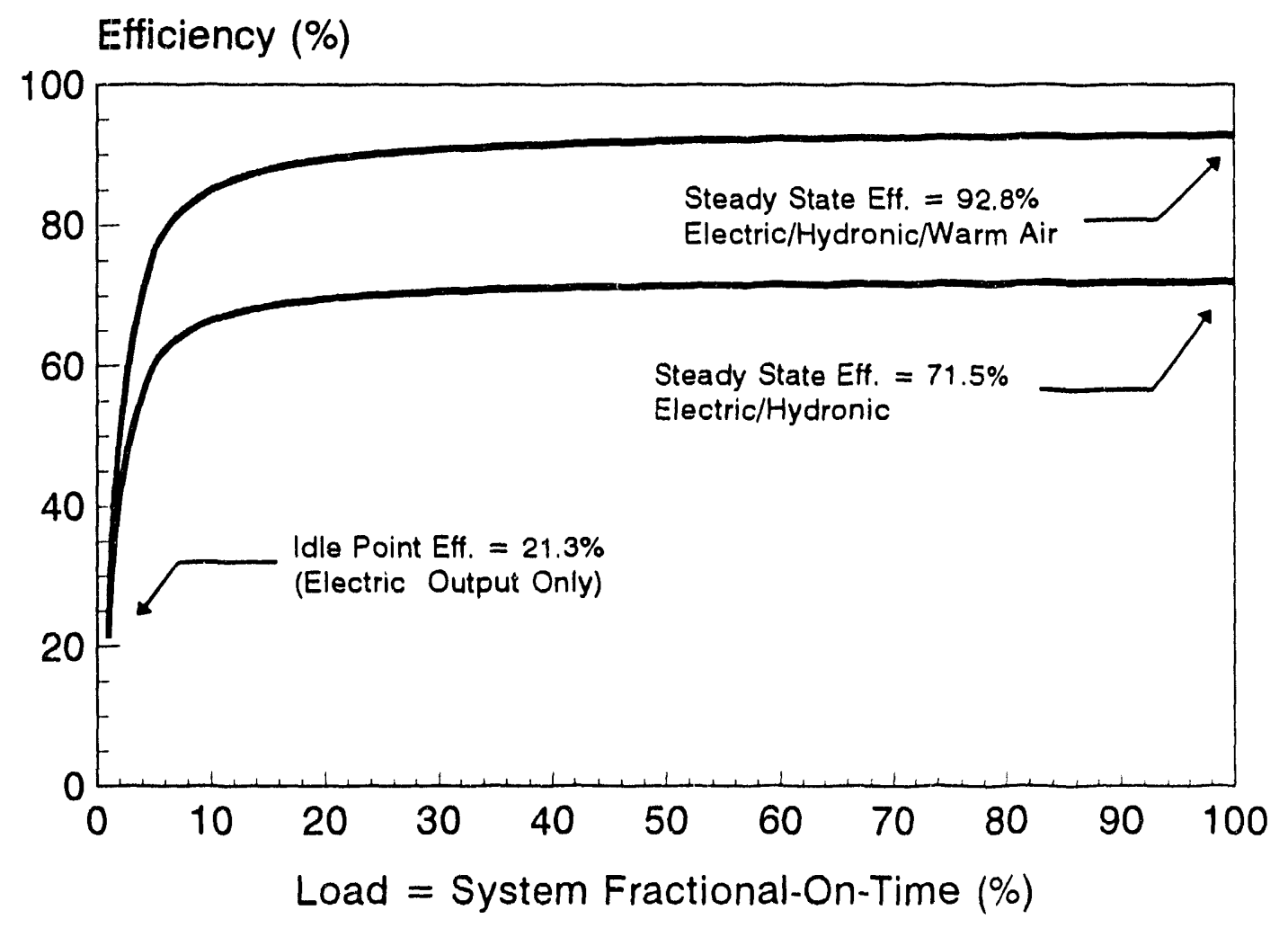

Figure 5: Test Results of Overall Efficiency Versus Load for the Intelligen Alpha-550 Cogenerator. 


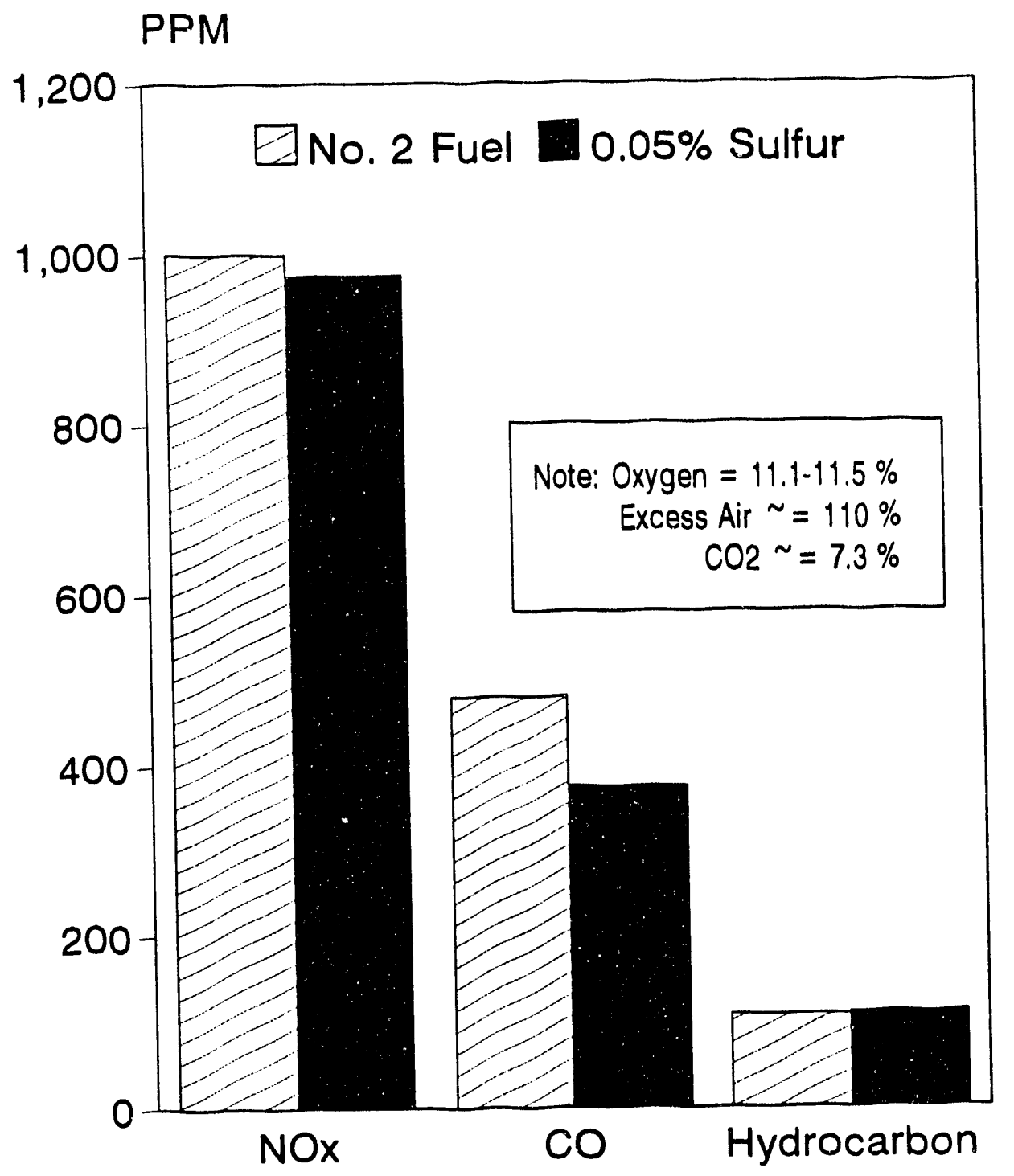

Figure 6: Results of Emission Measurements, $\mathrm{NO}_{\mathrm{x}} / \mathrm{CO} / \mathrm{Hydrocarbons,}$ Made During Steady-State operation for the Intelligen Alpha-550 Cogenerator. 


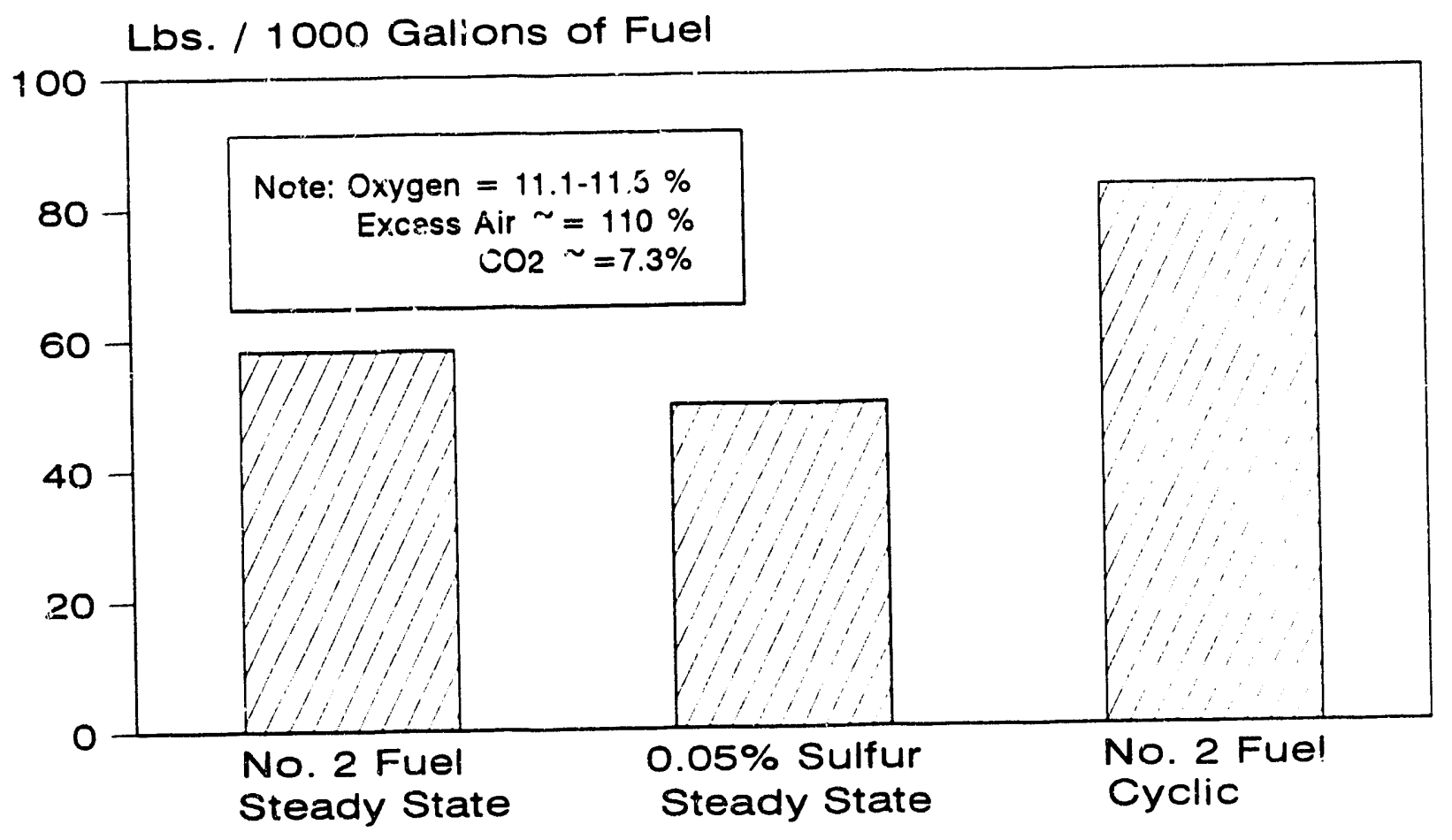

Figure 7: Results of the Emission Measurements, Particulates, Made During Steady-State and Cyclic operation for the Intelligen Alpha-550 Cogenerator. 


\section{Table 1}

\section{Emission Rates - Lbs. Per Million Btu Steady-State Operation}

No. 2 Fuel Oil $\quad 0.05 \%$ Sulfur Fuel

$\begin{array}{lcc}\text { Nitrogen Oxides (NOX) } & 2.26 & 2.21 \\ \text { Carbon Monoxide (CO) } & 0.66 & 0.52 \\ \text { Hydrocarbons } & 0.53 & 0.54 \\ \text { Particulates } & 0.42 & 0.36 \\ \text { Sulfur Dioxide } & 0.13 & 0.05\end{array}$

Note: $\mathrm{NO} \times, \mathrm{CO}$, and Hydrocarbons are calculated based on volumetric species measurements (parts per million). Sulfur dioxides were calculated based on the content of sulfur in the fuel and particulates which were measured directly. A cyclic particulate emission rate of 0.59 Lbs./Million Btu was measured for a 5 minute on / 15 minute off cycle using No. 2 fuel-oil. 
Sound Level dB

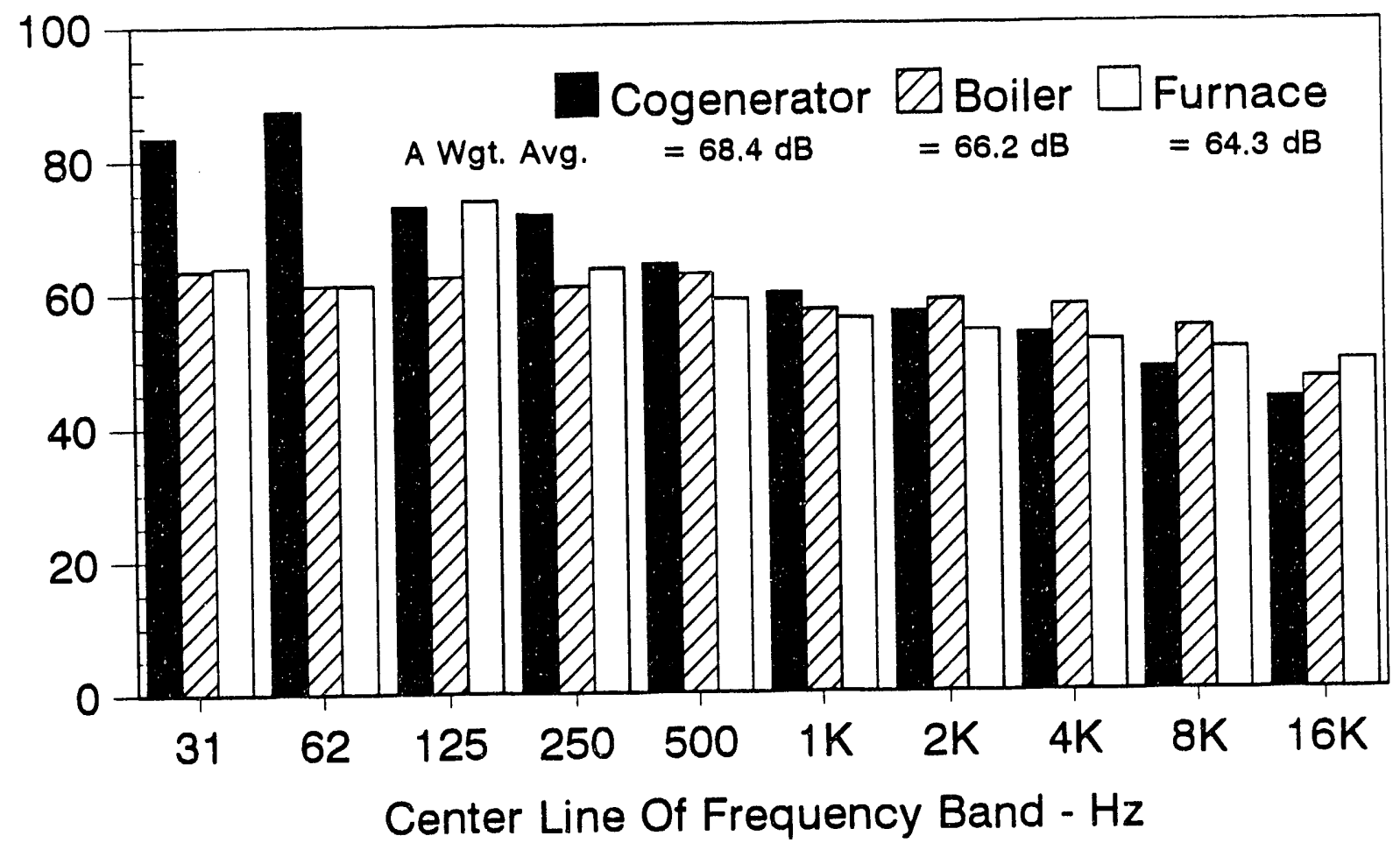

Figure 8: Results of the Noise Level Measurements, Made During Steady-state operation of the Intelligen Alpha-550. 


\subsection{CONCLUSIONS}

\section{System Efficiency}

The efficiency of the cogenerator system, at $92.8 \%$, represents a new high-end reference mark for the efficiency range of oil-fired residential heating equipment. Its efficiency can only be compared to "condensing" oil-fired residential furnaces which have AFUE ratings in the 90-91\% efficiency range. These condensing furnaces have the highest AFUE efficiency ratings of all the oil-fired heating systems in production.

The truly unique feature of the cogenerator is that approximately one-quarter of the output $(4.8 \mathrm{kw})$ is in the form of high quality electrical power. In a residential installation in the market areas targeted by the manufacturer, this will displace expensive electricity generated by utilities.

It can be argued that the electricity should be given a value approximately three times that of the heat, per unit of energy, when it displaces thermal utility power (non-hydroelectric) that would have resulted in two units of waste heat for each unit of electricity produced. If this is done, then the unit has an effective efficiency of $135 \%$.

The unit outputs $\sim 39,000 \mathrm{Btu} / \mathrm{hr}$ for hydronic circulation during normal heating conditions. When needed, this output is boosted up to $69,000 \mathrm{Btu} / \mathrm{hr}$ by electric water heating elements (which are directly powered by the cogenerator). These elements are located inside the circulating water system of the unit. When the system starts to heat a cold house, for example, after a power outage, or when outdoor temperatures are very low, these electric elements will be turned on by the microprocessor control unit to augment the hydronic heating output. As stated in section 4.0 a significant portion of the thermal energy is also output in the form of warm air, and to achieve the maximum efficiency of $92.8 \%$, this energy must be used effectively and not wasted. The location of the cogenerator inside a house and the design of the house will be important factors. The amount of warm air produced $(\sim 16,000 \mathrm{btu} / \mathrm{hr})$ represents $21.3 \%$ of the chemical energy in the No.2 fuel oil consumed by the engine during steady operation. If this energy is wasted, the overall efficiency is only $71.5 \%$.

\section{Environmental Emissions}

A comprehensive analysis of cogenerator emissions should include factors for the emissions reductions associated with the electricity generated at the utility power plant that this technology is intended to displace. This analysis is beyond the scope of the current engineering assessment. The emissions data contained in Figures 6 and 7 are representative of what is expected for a diesel engine of this size and type. This information has 
been included in this report so that others who wish to analyze regional emissions will have the necessary input data. All of the emission levels measured (Figures 6 and 7) are significantly higher than those measured for modern oil-fired heating systems equipped with flame retention head oil burners $\left[\mathrm{NO}_{\mathrm{x}}: \sim 100-150 \mathrm{ppm}\right.$; $\mathrm{CO}:-30 \mathrm{ppm}$ or less; hydrocarbons: $\sim 5 \mathrm{ppm}$ or less; and particulates: $\sim 0.4$ Ib per 1000 gallons of fuel or less (cyclic), and $\sim 0.1 \mathrm{lb} . / 1000 \mathrm{gal}$ or less (steady state)].

At this time, with the sole exception of limited areas in southern California (Los Angeles Basin), there are no federal, state, or local environmental emission performance requirements imposed on small residential heating systems manufactured for use in the United States. In addition, there are no published, pending, or announced plans by the U.S. Environmental Protection Agency to impose any federal regulations in the future. Emissions are not currently an issue that would impede the manufacture or marketing of diesel-engine-driven cogenexators, nor does it seem likely that it will be a problem any time in the future. currently, manufacturers of diesel engines are conducting a great deal of research and development to reduce engine emissions for diesel applications in the transportation sector. When successful, these innovations will be available and will very likely mitigate any air quality concerns associated with residential diesel-engine-driven cogenerators, such as the technology discussed in this report.

\section{Noise Levels}

The Intelligen unit was designed to operate quietly at noise levels comparable to those associated with more traditional oilfired appliances. The Model Alpha-550 tested at BNL exhibited very acceptable performance in this regard as shown in Figure 8 . All measurements, which were recorded only five feet from the unit, are well within OHSA standards for constant noise exposure. The "A" weighted average approximating the perception of the average human ear was well within measurement accuracy of the levels recorded for a boiler and a furnace tested on the same day at BNL (68.4 dB, 66.2 $\mathrm{dB}$, and $64.3 \mathrm{~dB}$ respectively, all $\pm 10 \%$ of reading). Taking into account that the BNL CETL is not a sound-measuring facility and that no special effort was made to attenuate or decouple the engine exhaust noise of the cogenerator, it is quite possible that the actual noise levels in the field may be slightly lower. The manufacturer has also stated that the unit sent to BNL was not equipped with all of the sound reducing features currently included in the cogenerator package.

The only other conclusion that can be drawn from the data is that the noise levels in the lower frequency bands are higher than those recorded for the furnace and the boiler. Low-frequency sounds are more difficult to attenuate than those at higher frequencies. The unit does have lower sound levels in the higher frequency ranges when compared to the furnace and the boiler. This is the reason that the overall weighted levels are approximately equal. Humans 
do not hear sounds in separate frequency bands, rather they hear sounds in unison. The "A" weighted procedure is a standard technique for predicting how humans will perceive the sound and is a good comparative representation of how things will sound. 


\subsection{RECOMMENDATIONS}

The prototype unit was well designed. It operated as expected based on the manufacturer's documentation provided before the evaluation. During the tests the unit failed to operate twice. In each case, the failure was traced to a problem related to a single component. In the first case, an electrical relay in the control system failed. The manufacturer diagnosed the problem quickly and the unit was repaired. The manufacturer has redesigned the control package to solve the problem in future production. In the second case a shaft key was omitted during assembly and resulted in a loose pulley, which damaged the auxiliary oil pump. This again was diagnosed and repaired very quickly. The problem will be corrected in the future by inspection during assembly. These problems were minor and typical of prototypes. The Alpha-550 unit tested at BNL was assembled at a time when there were only ten pre-production units in existence. These minor types of problems are why a manufacturer produces pre-production units for testing and limited field testing. All pre-production units should be carefully examined after the first year of operation to inspect components and subsystems that might indicate potential problems that can be corrected during future production or by improvements in design. The manufacturer has already indicated that several design changes are in progress.

The unit is intended to compete in the marketplace with more traditional heating systems, which do not produce electricity. This is a very competitive marketplace which is very sensitive to price levels. The cost of the unit should be controlled through "value" engineering and improvement in design. The prototype units appear to contain several subsystem assemblies put together by hand that could be redesigned to eliminate labor and complexity to save money.

To maintain environmental acceptability in the future, the manufacturers of small cogenerators, such as the unit tested at BNL, should incorporate new engine designs with low emission characteristics as they are developed. It would seem beyond the capacity of small, newly established manufacturers to pursue research in this area. However, other manufacturers are redesigning diesel engines for larger markets, such as the transportation sector, and this technology could possibly be adapted to cogenerator designs. 

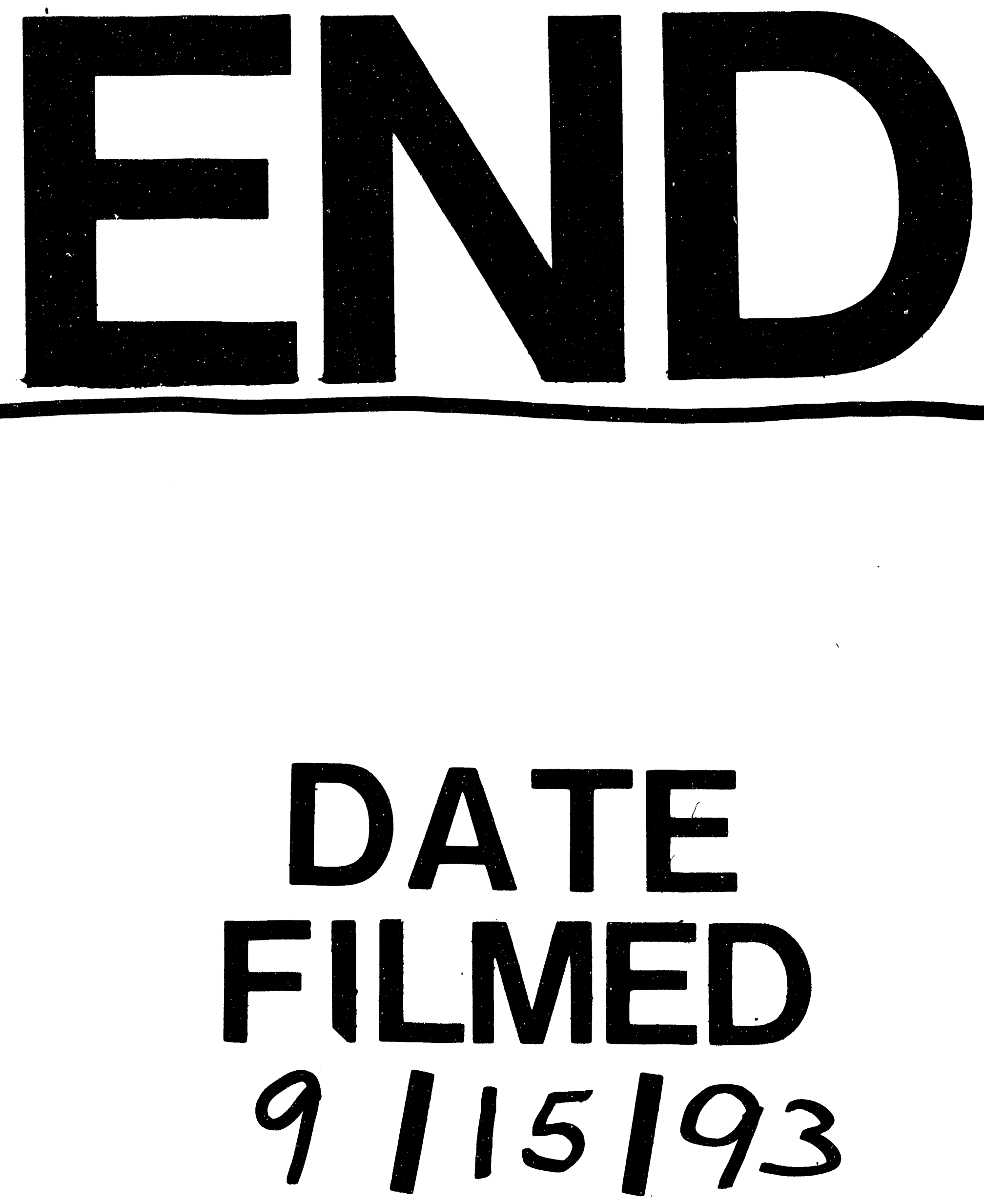
1 